\title{
The Challenges of Estimating Potential Output in Real Time
}

Robert W. Arnold

\begin{abstract}
Potential output is an estimate of the level of gross domestic product attainable when the economy is operating at a high rate of resource use. A summary measure of the economy's productive capacity, potential output plays an important role in the Congressional Budget Office (CBO)'s economic forecast and projection. The author briefly describes the method the CBO uses to estimate and project potential output, outlines some of the advantages and disadvantages of that approach, and describes some of the challenges associated with estimating and projecting potential output. Chief among these is the difficulty of estimating the underlying trends in economic data series that are volatile, subject to structural change, and frequently revised. Those challenges are illustrated using examples based on recent experience with labor force growth, the Phillips curve, and labor productivity growth. (JEL E17, E32, E62)
\end{abstract}

Federal Reserve Bank of St. Louis Review, July/August 2009, 91(4), pp. 271-90.

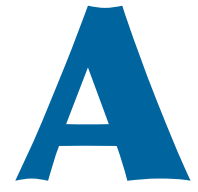

ssessing current economic conditions, gauging inflationary pressures, and projecting long-term economic growth are central aspects of the Congressional Budget Office (CBO)'s economic forecasts and baseline projections. Those tasks require a summary measure of the economy's productive capacity. That measure, known as potential output, is an estimate of "full-employment" gross domestic product (GDP)— the level of GDP attainable when the economy is operating at a high rate of resource use. Although it is a measure of the productive capacity of the economy, potential output is not a technical ceiling on output that cannot be exceeded. Rather, it is a measure of sustainable output, where the intensity of resource use is neither adding to nor subtracting from short-run inflationary pressure. If actual output exceeds its potential level, then constraints on capacity begin to bind, restraining further growth and contributing to inflationary pressure. If output falls below potential, then resources are lying idle and inflation tends to fall.

In addition to being a measure of aggregate supply in the economy, potential output is also an estimate of trend GDP. The long-term trend in real GDP is generally upward as more resourcesprimarily labor and capital-become available and technological change allows more productive use of existing resources. Real GDP also displays short-term variation around that long-run trend, influenced primarily by the business cycle but also by random shocks whose sources are difficult to pinpoint. Analysts often want to estimate the underlying trend, or general momentum, in GDP by removing short-term variation from it. A distinct, but related, objective is to remove the fluctuations that arise solely from the effects of the business cycle.

Potential output plays a role in several areas associated with the CBO's economic forecast. In particular, we use potential output to set the level of real GDP in its medium-term (or 10-year)

Robert W. Arnold is principal analyst in the Congressional Budget Office.

(C) 2009, The Federal Reserve Bank of St. Louis. The views expressed in this article are those of the author(s) and do not necessarily reflect the views of the Federal Reserve System, the Board of Governors, or the regional Federal Reserve Banks. Articles may be reprinted, reproduced, published, distributed, displayed, and transmitted in their entirety if copyright notice, author name(s), and full citation are included. Abstracts, synopses, and other derivative works may be made only with prior written permission of the Federal Reserve Bank of St. Louis. 
projections. In doing so, we assume that the gap between GDP and potential GDP will equal zero on average in the medium term. Therefore, the CBO projects that any gap that remains at the end of the short-term (or two-year) forecast will close during the following eight years. We also use the level of potential output as one gauge of inflationary pressures in the near term. For example, an increase in inflation that occurs when real GDP is below potential (and monetary growth is moderate) can probably be attributed to temporary factors and is unlikely to persist. Finally, potential output is an important input in computing the standardized-budget surplus or deficit, which the CBO uses to evaluate the stance of fiscal policy and reports regularly as part of its mandate.

\section{THE CBO METHOD FOR ESTIMATING POTENTIAL OUTPUT}

The CBO model for estimating potential output is based on the framework of a neoclassical, or Solow, growth model. The model includes a Cobb-Douglas production function for the nonfarm business (NFB) sector with two factor inputs, labor (measured as hours worked) and capital (measured as an index of capital services provided by the physical capital stock), and total factor productivity (TFP), which is calculated as a residual. NFB is by far the largest sector in the economy, accounting for 76 percent of GDP in 2007, compared with less than 10 percent for each of the other sectors. For smaller sectors of the economy, including farms, federal government, state and local government, households, and nonprofit institutions, simpler equations are used to model output. Those equations generally relate the growth of output in a sector to the growth of the factor input-either capital or labor-that is more important for production in that sector. ${ }^{1}$

To compute historical values for potential output, we cyclically adjust the factor inputs and then combine them using the production function. Cyclical adjustment removes the variation in a

1 This section gives an overview of the CBO method. For a more complete description, see CBO (2001). series that is attributable solely to business cycle fluctuations. Ideally, the resulting series will reflect not only the trend in the series, but also will be benchmarked to some measure of capacity in the economy and, therefore, can be interpreted as the potential level of the series.

For most variables in the model, we use a cyclic-adjustment equation that combines a relationship based on Okun's law with linear time trends to produce potential values for the factor inputs. Okun (1970) postulated an inverse relationship between the size of the output gap (the percentage difference between GDP and potential GDP) and the size of the unemployment gap (the difference between the unemployment rate and the "natural" rate of unemployment). According to that relationship, actual output exceeds its potential level when the unemployment rate is below the natural rate of unemployment and falls short of potential output when the unemployment rate is above its natural rate (Figure 1).

For the natural rate of unemployment, we use the $\mathrm{CBO}$ estimate of the non-accelerating inflation rate of unemployment (NAIRU). That rate corresponds to a particular notion of full employmentthe rate of unemployment that is consistent with a stable rate of inflation. The historical estimate of the NAIRU derives from an estimated relationship known as a Phillips curve, which connects the change in inflation to the unemployment rate and other variables, including changes in productivity trends, oil price shocks, and wage and price controls. The historical relationship between the unemployment gap and the change in the rate of inflation appears to have weakened since the mid1980s. ${ }^{2}$ However, a negative correlation still exists; when the unemployment rate is below the NAIRU, inflation tends to rise, and when it exceeds the NAIRU, inflation tends to fall. Consequently, the NAIRU, while it is less useful for inflation forecasts, is still useful as a benchmark for potential output.

The assumption of linear time trends in the cyclic-adjustment equation implies that the poten-

\footnotetext{
2 For a description of the procedure used to estimate the NAIRU, see Arnold (2008).
} 


\section{Figure 1}

\section{Okun's Law: The Output Gap and the Unemployment Gap}

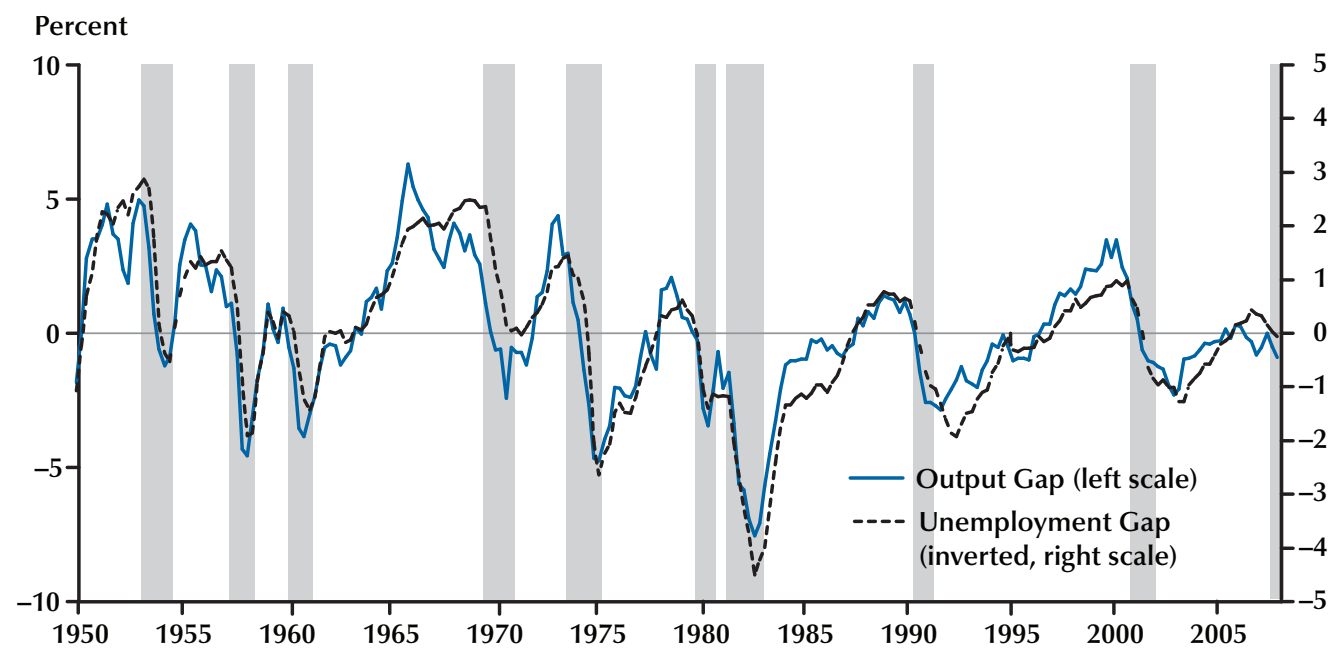

NOTE: Gray bars in Figures 1, 2, 3, 5, 6, and 8 indicate recession as determined by the National Bureau of Economic Research.

tial version of each variable grows at a constant rate during each historical business cycle. Rather than constraining the potential series to follow a single time trend throughout the entire sample, the model allows for several time trends, each beginning at the peak of a business cycle. Defining the intervals of the time trends using full business cycles helps to ensure that the trends are estimated consistently throughout the historical sample. Most economic variables have distinct cyclical patterns-they behave differently at different points in the business cycle. Specifying breakpoints for the trends that occur at different stages of different business cycles (say, from trough to peak) would likely provide a misleading view of the underlying trend.

The cyclic-adjustment equation has the following form:

$$
\begin{aligned}
& \log (X)=\text { Constant }+\alpha\left(U-U^{*}\right) \\
& +\beta_{1} T_{1953}+\beta_{2} T_{1957}+\ldots+\beta_{8} T_{1990}+\varepsilon,
\end{aligned}
$$

where $X=$ the series to be cyclically adjusted,

$U=$ unemployment rate,

$U^{*}=$ NAIRU, and
$T_{i}=$ zero until the business-cycle peak occurring in year $i$, after which it equals the number of quarters elapsed since that peak.

Equation (1), a piecewise linear regression, is estimated using quarterly data and ordinary least squares. Potential values for the series being adjusted are calculated as the fitted values from the regression, with $U$ constrained to equal $U^{*}$. Setting the unemployment rate to equal the NAIRU removes the estimated effects of fluctuations in the business cycle; the resulting estimate gives the equation's prediction of what the dependent variable $(X)$ would be if the unemployment rate never deviated from the NAIRU. An example of the results of using the cyclic-adjustment equation is illustrated in Figure 2, which shows TFP and potential TFP.

One question that arises is when to add a new trend break to the equation. Typically, we do not add a new breakpoint immediately after a business cycle peak because doing so would create, at least initially, a very short trend segment for the period after the peak. Such a segment would be subject to large swings as new data points were added 
Figure 2

\section{TFP and Potential TFP}

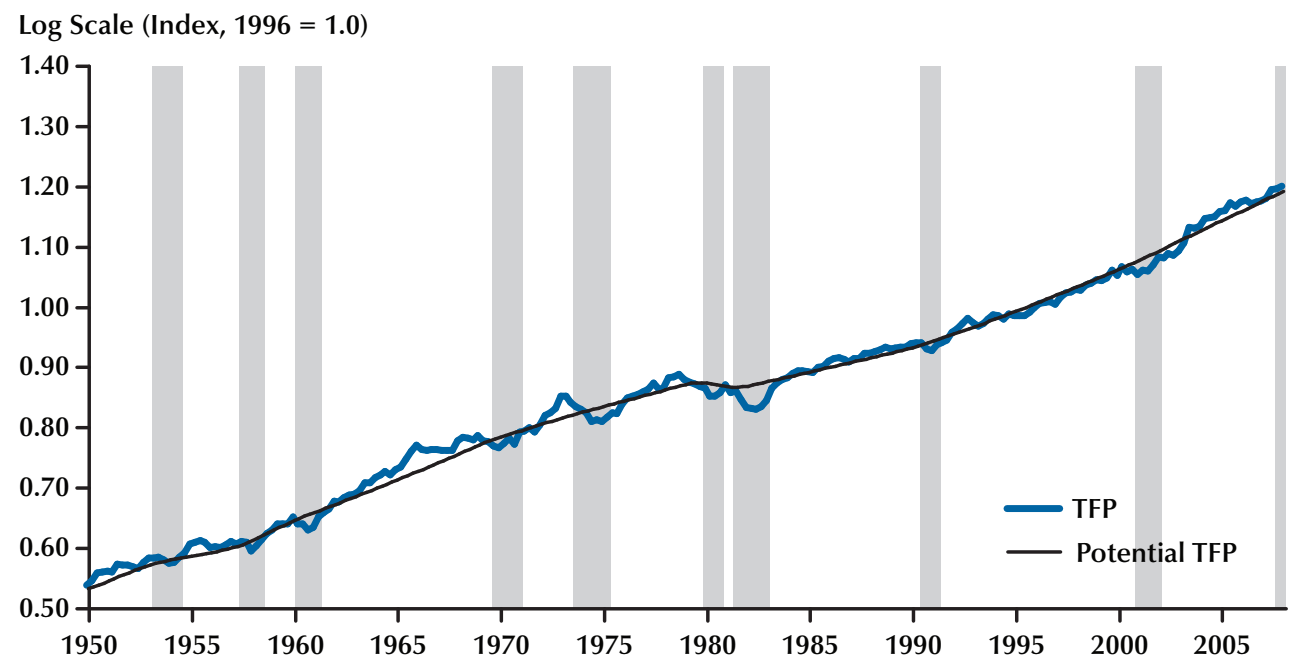

to the sample because it was so short, at least initially. Because the final segment of the trend is carried forward into the projection, those swings would create instability to our medium-term projections. Consequently, we typically wait until a full business cycle has concluded before adding a new break to the trend. For example, the model does not yet include a break in 2001, though the addition of one appears to be increasingly likely.

Equation (1) is used for most, but not all, inputs in the model. One important exception is the capital input, which does not need to be cyclically adjusted to create a "potential" level because the unadjusted capital input already represents its potential contribution to output. Although use of the capital stock varies greatly during the business cycle, the potential flow of capital services is always related to the total size of the capital stock, not to the amount currently being used. Other exceptions include several variables of lesser importance that do not vary with the business cycle. Those series are smoothed using the Hodrick-Prescott filter.

As noted earlier, the method for computing historical values of potential output in the other sectors of the economy differs slightly from that used for the NFB sector. In general, the approach is to express real GDP in each of the other sectors as a function of the primary factor input (either labor or capital) in that sector and the productivity of that input. The potential levels of the primary input and its productivity are cyclically adjusted using an analog to equation (1) and then combined to estimate potential output in that sector. The list below describes how each sector is modeled.

- Farm sector: Potential GDP in this sector is modeled as a function of potential farm employment and potential output per employee.

- Government sector: Potential GDP in this sector is the sum of potential GDP in the federal government and state and local governments. Potential GDP at each level of government equals the sum of the compensation of general government employees (adjusted to potential) and government depreciation. Compensation is modeled as a function of total employment, and compensation per employee and depreciation is modeled as a function of the government capital stock.

- Nonprofit sector: Potential GDP in this sector is modeled as a function of potential 
nonprofit employment and potential output per employee.

- Household sector: Although some of the GDP in the household sector consists of the compensation of domestic workers, the majority is composed of imputed rent on owner-occupied housing. As such, output in this sector is composed of a stream of housing services provided almost entirely from the capital stock. Potential GDP in this sector is modeled as a function of the stock of owner-occupied housing and an estimate of the productivity of that stock. Similar to the capital input in the NFB sector, the housing capital stock is not adjusted to potential because the unadjusted stock reflects the potential contribution to output.

For projections of potential output, the same framework is used for these sectors as is used for the NFB sector. Given projections of several exogenous variables-of which potential labor force, potential TFP growth, and the national saving rate are the most important- the growth model computes the capital stock endogenously and combines the factor inputs into an estimate of potential output. In most cases, projecting the exogenous variables is straightforward: The CBO generally extrapolates the trend growth rate from recent history through the 10 -year projection period. However, the projections for some exogenous variables, most notably the saving rate, are taken from the CBO economic forecast.

\section{Advantages and Disadvantages of the CBO Method}

The CBO method for estimating and projecting potential output has several key advantages. First, it looks explicitly at the supply side of the economy. Potential output is a measure of productive capacity, so any estimate of it is likely to benefit from explicit dependence on factors of production. For example, if growth in the available pool of labor increases, then this method will show an acceleration in potential output (all other things being equal). With our approach, an increase in investment spending would also be reflected in faster growth in productive capacity.
Another advantage of a growth model is that it allows for a transparent accounting of the sources of growth. Such a growth-accounting exercise, which divides the growth of potential GDP into the contributions from each of the factor inputs, is especially useful when explaining the factors that caused a change to $\mathrm{CBO}$ projections. A growthaccounting exercise for our current projection is shown in Table $1 .^{3}$ The table displays the growth rates of potential output and its components for the overall economy and the NFB sector. Note that the growth rates of the factor inputs (top and middle panels of the table) are not weighted; they do not sum to the growth in potential output.

A third advantage of using a growth model to calculate potential output is that it supplies a projection for potential output that is consistent with the CBO projection for the federal budget. That consistency allows the CBO to incorporate the effects of changes in fiscal policy into its medium-term (10-year) economic and budget projections. Fiscal policy has obvious effects on aggregate demand in the short run, effects that are reflected in our short-term forecast. However, fiscal policy will also influence the growth in potential output over the medium term through its effect on national saving and capital accumulation. Because the growth model explicitly includes capital as a factor of production, it captures that effect.

Table 1 also shows the contribution of each factor input to the growth of potential output in the NFB sector by weighting each input's growth rate by its coefficient in the production function. The sum of the contributions equals the growth of potential output in the NFB sector. Computing the contributions to growth highlights the sources of any quickening or slowdown in growth. For example, the $\mathrm{CBO}$ estimates that potential output in the NFB sector grew at an average annual rate of 3.3 percent during the $1982-90$ period and 3.5 percent during the 1991-2001 period. That acceleration can be attributed to faster growth in the capital input (which contributed 1.2 percentage points to the growth of potential output during the first period and 1.4 percentage points in the

\footnotetext{
3 See CBO (2008).
} 


\section{Arnold}

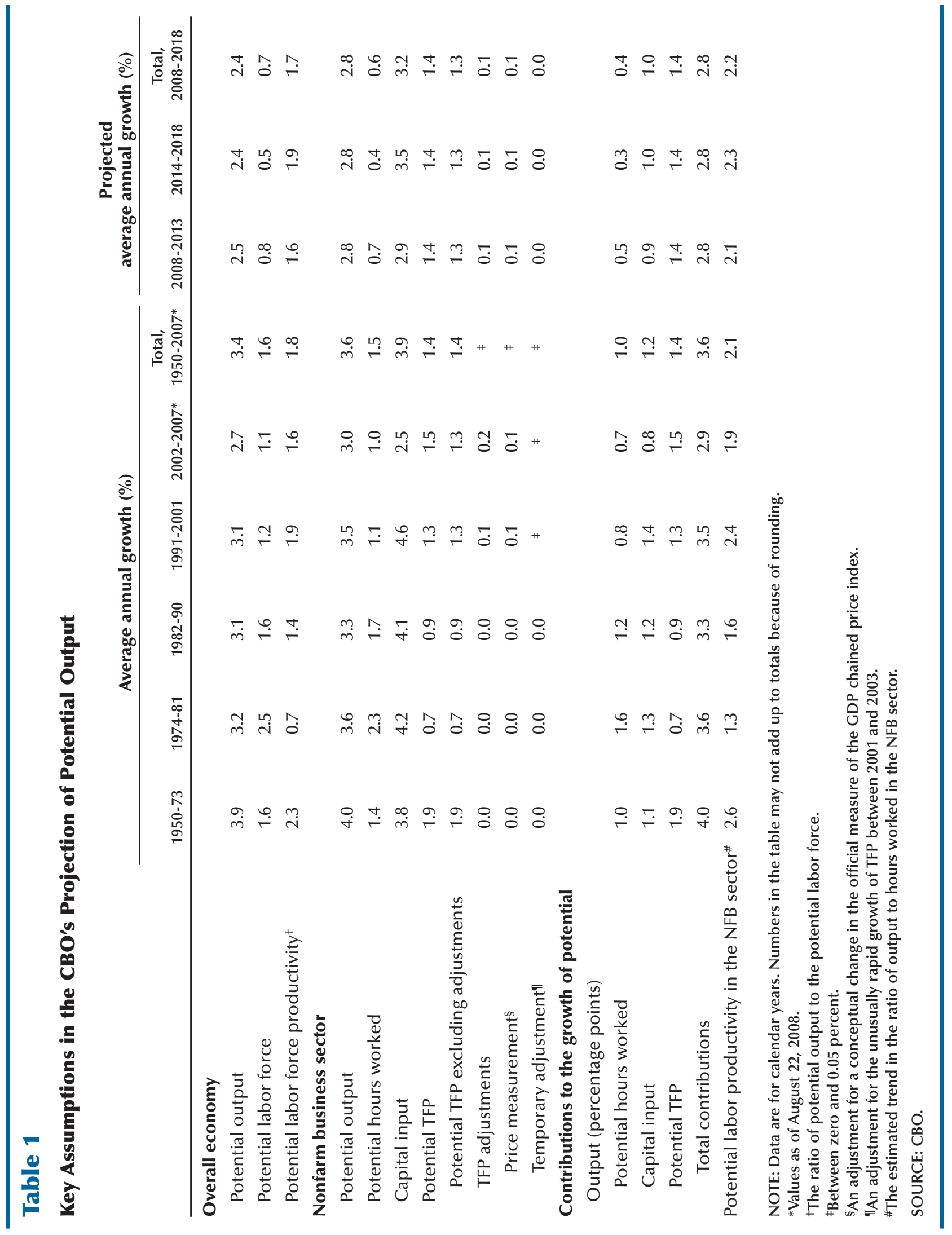


second) and faster growth of potential TFP (which contributed 0.9 and 1.3 percentage points to the growth of potential output during the two periods, respectively). Faster growth in those two factors more than offset a slowdown in potential hours worked between the two periods. This point is addressed later.

Fourth, by using a disaggregated approach, the CBO method can reveal more insights about the economy than a more-aggregated model would. For example, the model calculates the capital input to the production function as a weighted average of the services provided by seven types of capital. Those data indicate a shift over the past few decades to capital goods with shorter service lives: A larger share of total fixed investment is going to producers' durable equipment (PDE) relative to structures, and a larger share of $\mathrm{PDE}$ is going to computers and other information technology (IT) capital. Because shorter-lived capital goods depreciate more rapidly, the shift toward PDE and IT capital increases the share of investment dollars used to replace worn-out capital and tends to lower net investment and the capital input. Shorter-lived capital goods are also more productive per year of service life than those that last longer and are therefore weighted more heavily in the growth model's capital input. A model that ignores the capital input or that does not disaggregate capital is likely to miss both of those effects.

On the negative side, the simplicity of our model could be perceived as a drawback. The model uses some parameters-most notably, the coefficients on labor and capital in the production function-that are imposed rather than econometrically estimated. Although that approach is standard practice in the growth-accounting literature (in part because it has empirical support), it is tantamount to assuming the magnitude of the contribution that each factor input makes to growth. With such an approach, the magnitude of that contribution will not change from year to year as the economy evolves, as it would in an econometrically estimated model. Moreover, it requires some strong assumptions that may not be consistent with the data.
A second disadvantage of using a growth model to estimate potential output is that including the capital stock introduces measurement error. Most economic variables are subject to measurement error, but the problem is particularly acute for capital, for two basic reasons. First, measuring the stock of any particular type of capital is difficult because depreciation is hard to define or measure. Purchases of plant and equipment can be tallied to produce a historical series for investment, but no corresponding source of data exists for depreciation. Second, even if accurate estimates of individual stocks were available, aggregating them into a single index would be difficult because capital is heterogeneous, differing with respect to characteristics such as durability and productivity. ${ }^{4}$

A third point of contention regarding the CBO approach is the use of deterministic time trends to cyclically adjust many variables in the model. Some analysts assert that relying on fixed time trends provides a misleading view of the cyclical behavior of some economic time series. They argue, on the basis of empirical studies of the business cycle, that using variable rather than fixed time trends is more appropriate for most data series. ${ }^{5}$ However, the evidence on this point is mixed-it is very difficult to determine whether the trend in a data series is deterministic or stochastic using existing econometric techniquesand the methods used to estimate stochastic trends often yield results that are not useful for estimating potential output. That is, stochastic trends tend to produce estimates of the output gap that are not consistent with other indicators of the business cycle.

Fourth, the CBO growth model is based on an estimate of the amount of slack in the labor market, which in turn requires an estimate of the natural rate of unemployment or the NAIRU. Such

\footnotetext{
4 The CBO capital input uses capital stock estimates (and the associated assumptions about depreciation) from the Bureau of Economic Analysis and uses an aggregation equation that is based on the approach used by the Bureau of Labor Statistics (BLS) to construct the capital input that underlies the multifactor productivity series. The CBO estimate of the capital input is quite similar to that calculated by the BLS.

5 See, for example, Stock and Watson (1988).
} 
estimates are highly uncertain. Few economists would claim that they can confidently identify the current NAIRU to within a percentage point. Our method is not very sensitive to possible errors in the average level of the estimated NAIRU, but it is sensitive to errors in identifying how that level changes from year to year.

Finally, the CBO model does not contain explicit channels of influence for all major effects of government policy on potential output. For example, it does not include an explicit link between tax rates and labor supply, productivity, or the personal saving rate; nor does it include any link between changes in regulatory policy and those variables. However, that does not mean that the model precludes a relationship between policy changes and any of those variables. If a given policy change is estimated to be large enough to affect the incentives governing work effort, productivity, or saving, then those effects can be included in our projection or in a policy simulation by adjusting the relevant variable in the model. For example, changes in marginal tax rates have the potential to affect labor supply. Because the Solow model does not explicitly model the factors that affect the labor input, our model includes a separate adjustment to incorporate such effects. Indeed, for the past several years, such an adjustment has been included in our model to account for the effects on the labor supply of the scheduled expiration in 2011 of the tax laws passed in 2001 and 2003. The structure of our model makes it easier to isolate (and incorporate) the effects of such policy changes than would be the case with a time-series-based model.

\section{CHALLENGES ASSOCIATED WITH ESTIMATING AND PROJECTING POTENTIAL OUTPUT}

Potential output plays a key role in the CBO economic forecast and projection. Perhaps the two most important are estimating the output gap (percentage difference between GDP and potential GDP) and providing a target for the 10 -year projection of GDP. Important challenges are associated with both roles.

\section{Challenges Associated with Estimating the Output Gap}

Any method used to estimate the trend in a series, including potential output, is subject to an "end-of-sample" problem, which means that estimating the trend is especially difficult near the end of a data sample. In the case of the output gap, this is usually the period of greatest interest. Three examples from the period since 2000 illustrate the difficulties associated with estimating the level of potential output at the end of the sample period.

Potential Labor Force. Fundamentally, the amount of hours worked in the economy is determined by the size of the labor force, which, in turn, is largely influenced by two factors: growth in the population and the rate of labor force participation. Neither of those series is especially sensitive to business cycle fluctuations, but both are subject to considerable low-frequency variation. The discussion here focuses on how the rate of labor force participation has changed during recent years and how we have modified the CBO labor force projections as a result.

After a long-running rise that started in the early 1960s, the labor force participation rate plateaued at about 67 percent of the civilian population during the late 1990s, declined sharply between 2000 and 2003, and varied in a narrow range near 66 percent between 2003 and 2008 (Figure 3). Had that decline in the participation rate not occurred, the labor force would have had approximately 2.3 million more workers in 2008 than it actually did.

To assess its impact on potential output, the challenge during the early 2000s was to determine whether the decline in the participation rate was cyclical (i.e., workers had dropped out of the labor force because their prospects of getting a job were dim) or structural (i.e., prospective labor force participants had weighed the alternatives and found that options such as education, retirement, or child-rearing were more attractive). If the decline were due to cyclical reasons, then the dip in participation should not be reflected in the estimate of potential labor force. If the decline were due to structural reasons, however, then the 


\section{Figure 3}

\section{Labor Force Participation Rate}

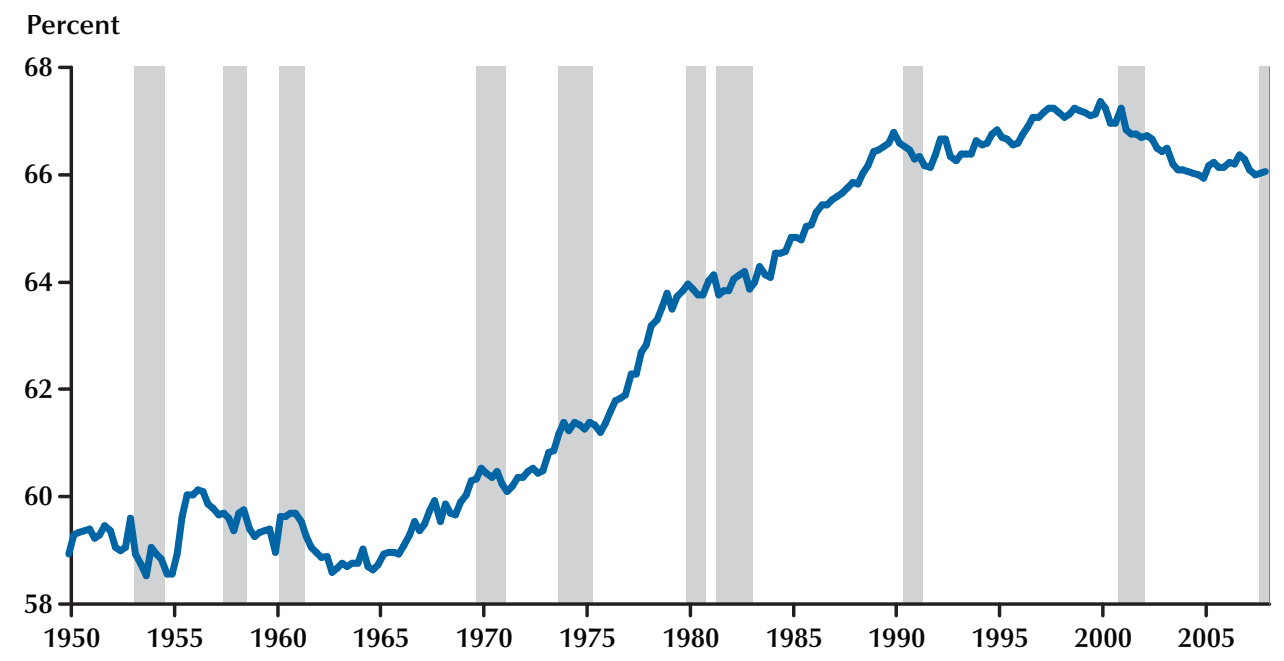

estimates of potential labor force and potential output should be lowered to reflect the decreased size of the potential workforce.

The drop in the participation rate also complicated the interpretation of movements in the unemployment rate, which peaked at 6.1 percent in mid-2003 and declined thereafter. During 2006 and 2007, the unemployment rate was below 5 percent, which suggested considerable tightness in the labor market. However, the decline in the participation rate implied that there existed a pool of untapped labor that could have been drawn into the workforce had there been a significant speedup in the pace of job creation. Consequently, at that time, the unemployment rate probably understated the degree of slack that existed in the labor market. Indeed, in the early stages of the expansion following the 2001 recession, we projected that the participation rate would recover as job creation picked up. It never did though, and the CBO has since concluded that the decline in the participation rate was more structural than cyclical. ${ }^{6}$

\footnotetext{
6 That conclusion was based on an analysis of the factors affecting the participation rates of various demographic subgroups in the population; see CBO (2004).
}

Potential NFB Employment. The second challenge is associated with the behavior of employment since the end of the 2001 recession and its implications for the estimate of potential hours worked in the NFB sector. One striking feature of the economic landscape since the 2001 business cycle trough is very weak growth in employment, especially for measures derived from the Bureau of Labor Statistics' establishment survey. For example, since the trough in the fourth quarter of 2001, growth in nonfarm payroll employment averaged 0.8 percent at an annual rate, which means that payrolls were roughly 5 percent higher in the second quarter of 2008 than they were at the end of the 2001 recession. However, based on patterns in past cycles, one would have expected much faster growth in payroll employment-2.4 percent on average-and a much higher level of employment-17 percent higher than its trough value-by the second quarter of 2008 (Figure 4).

A similar pattern holds for employment in the NFB sector (which differs from the headline payroll number by excluding employees in private households and nonprofit institutions and including proprietors). In the second quarter of 2008, NFB employment was about 4 percent above 
Figure 4

Payroll Employment in the Current Expansion Compared with an "Average" Cycle

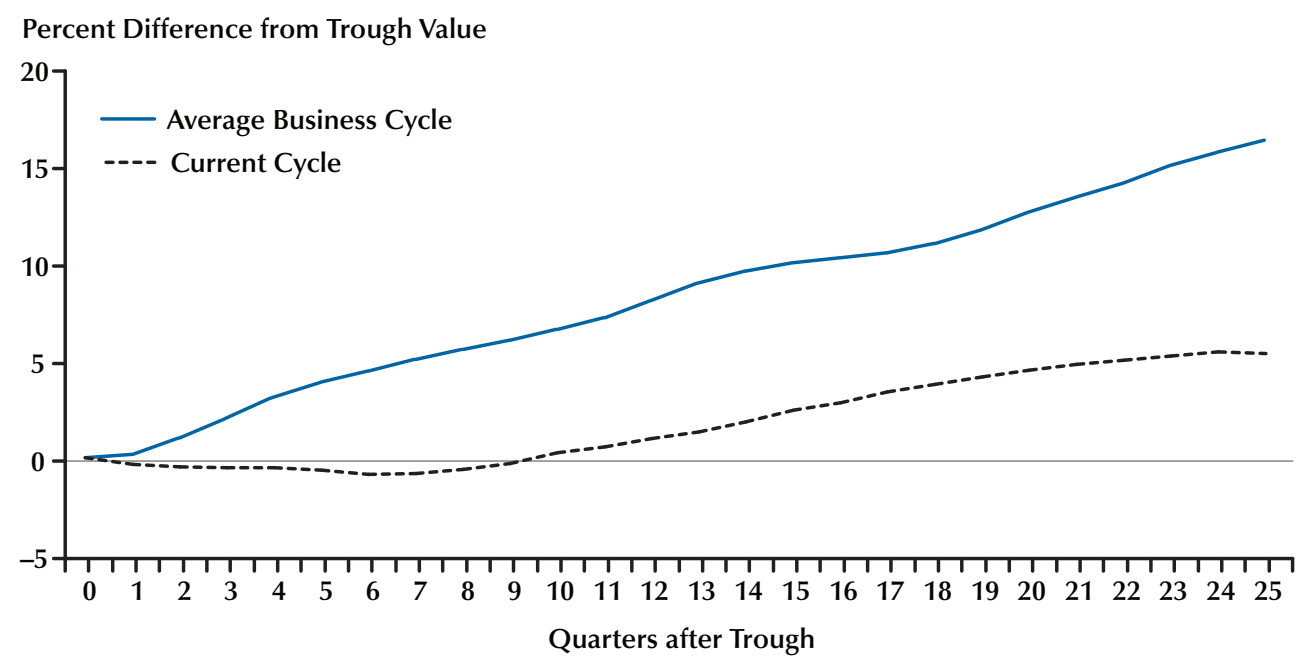

Figure 5

NFB Sector Employment as a Percent of the Civilian Labor Force

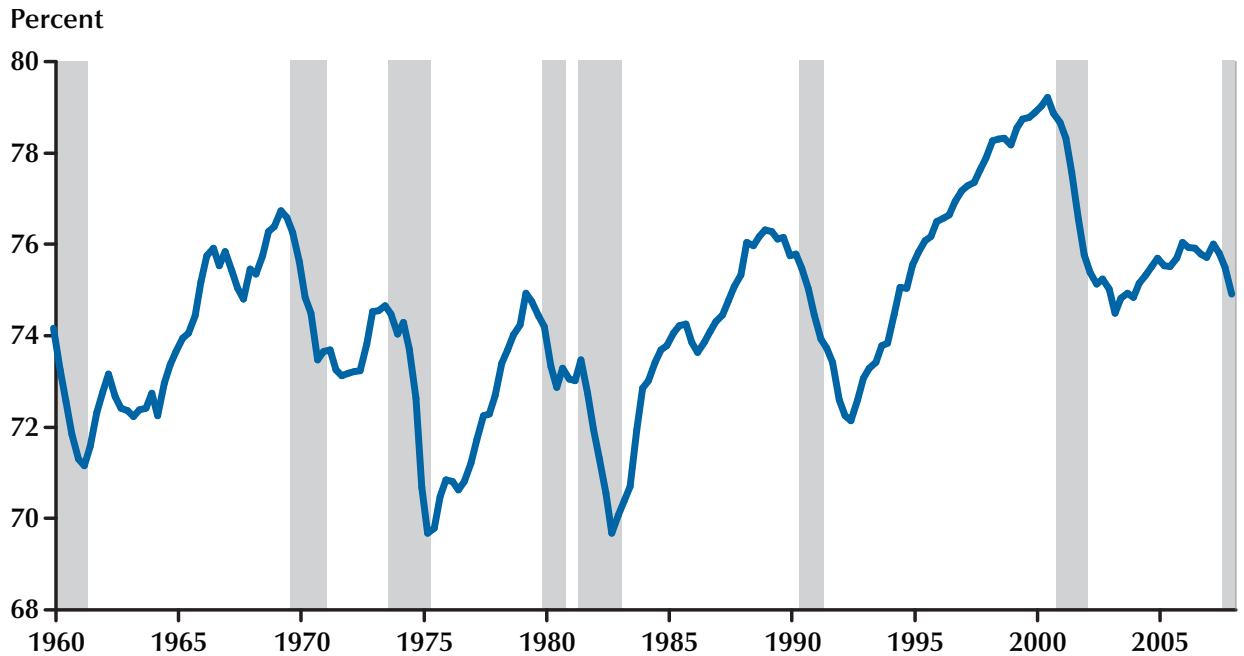




\section{Figure 6}

\section{NFB Employment as a Percent of the Civilian Labor Force and Two Counterfactual Paths}

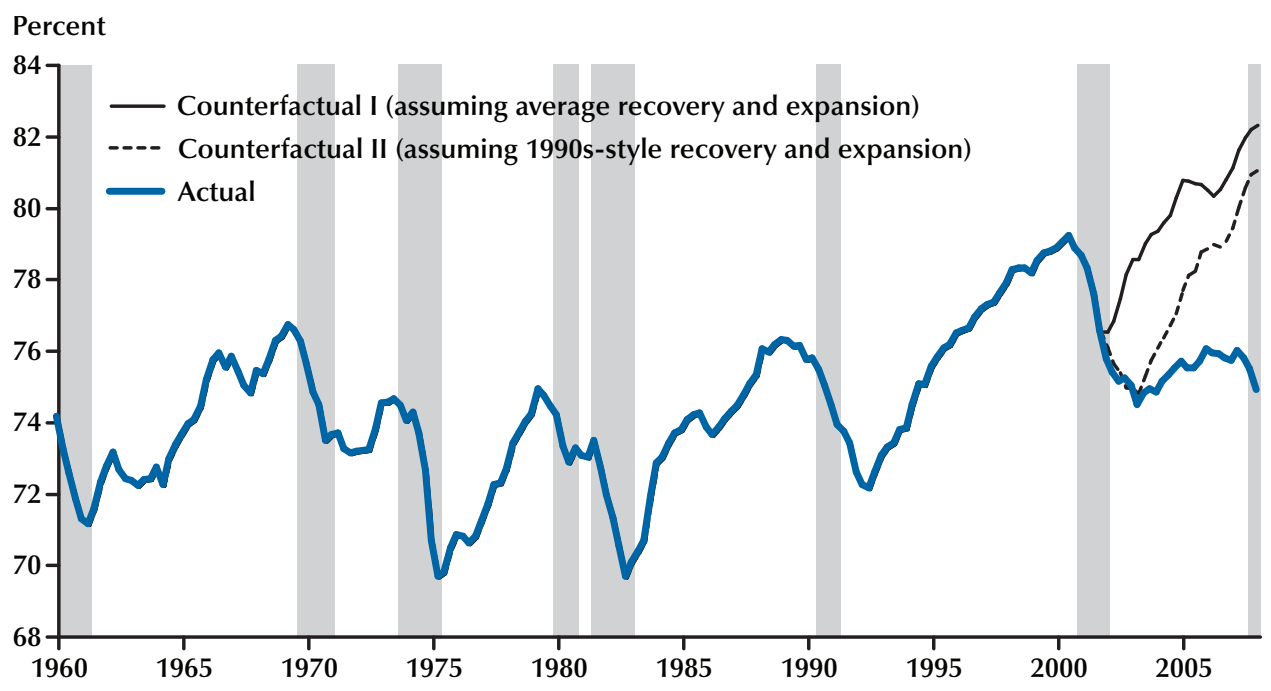

its level at the end of the 2001 recession. Had it grown according to the pattern seen in a typical business cycle expansion, it would have been about 15 percent higher than its level at the trough of the recession.

The behavior of NFB employment since the business cycle peak in 2001 also looks very unusual when viewed from another perspective. When measured as a share of the labor force (which controls for the decline in the rate of labor force participation), NFB employment barely grew during the expansion that followed the 2001 recession (Figure 5). This is extremely unusual on two counts. First, it departs from the very strong procyclical pattern seen in most recovery and expansion periods. Typically, NFB sector employment grows much faster than the labor force during business cycle expansions, which causes a rapid increase in its share. Second, the recent behavior breaks with the long-standing upward trend in the NFB share of the labor force. Since roughly the mid-1970s, trend growth in NFB employment has exceeded trend growth in the labor force on average, leading to a steady increase in the share. Examining the peaks is a rough-andready way to control for business cycle variation:
The share increased from about 74 percent in 1973, to just under 75 percent in 1979, to just over 76 percent in 1989, to just under 80 percent in 1999.

After the trough in 2001, the share of NFB employment declined for another two years and then increased somewhat but not anything like a normal cyclical rebound. The reasons for this behavior are not fully clear-shifts of employment to other sectors, including government and nonprofit institutions, can explain only part of the shortfall—but it has important implications for the estimate of potential employment and hours worked. Specifically, the estimate of potential employment in the NFB sector is much lower than it would have been had actual NFB employment followed a more typical cyclical pattern since 2001.

To illustrate this point, consider what the NFB employment share would have looked like had it followed a more typical cyclical pattern. Figure 6 shows NFB employment as a share of the labor force along with two counterfactual paths for the share. The thin solid line shows the evolution of the NFB employment share had it grown since 2001 at the same rate as an "average" historical expansion. That path embodies much stronger 
employment growth than does the actual path and would imply a much higher level of potential employment as well. Arguably, that path is too strong, given that employment growth has been sluggish in the recoveries that followed the past two recessions. So the figure includes a second counterfactual path (dotted line) showing the evolution of the NFB employment share had it grown as it did during the expansion of the 1990s. It too implies much stronger employment growth than actually occurred.

For the first few years of the current business cycle, it was reasonable to expect a typical rebound in the NFB employment share, even if it was delayed relative to past expansions. If so, then the period of sluggish growth in NFB employment could be interpreted as a cyclical pattern and would not necessarily imply that the level of potential NFB employment was lower. However, as the period of sluggish growth grew longer and in light of the possibility of a business cycle peak in early 2008, the position that NFB employment would eventually rebound became increasingly untenable.

Instead, it seems increasingly likely that NFB employment will merely match the growth in the labor force in the future, rather than grow at a faster pace. One implication of that interpretation is that the experience of the late 1990s, when the NFB employment share of the labor force was very high, was unusual and is unlikely to be repeated.

Changes in the Phillips Curve and NAIRU. As noted previously, the natural rate of unemployment is an important input in the CBO model. It serves as the benchmark used to estimate the potential values of the factor inputs and, consequently, potential output. Any uncertainties associated with the size of the unemployment gap, or difference between the unemployment rate and the natural rate, will translate directly into uncertainty about the size of the output gap.

Our estimate of the natural rate, known as the NAIRU, is based on a standard Phillips curve, which relates changes in inflation to the unemployment rate, expected inflation, and various supply shock variables. In particular, the NAIRU estimate relies on the existence of a negative correlation between inflation and unemployment: If inflation tends to rise when the unemployment rate is low and tends to fall when the unemployment rate is high, then there must be an unemployment rate at which there is no tendency for inflation to rise or fall. This does not mean that the rate is stable or that it is precisely estimated, just that it must exist.

However, during the past 20 or so years, significant changes in how the economy functions have affected the relationship between inflation and unemployment and, consequently, estimates of the Phillips curve and the NAIRU. Most notably, the rate of inflation has been lower and much less volatile since the mid-1980s, a phenomenon often referred to as the Great Moderation. At the same time, the unemployment rate has trended downward, which suggests that the natural rate of unemployment has declined also. Researchers had identified several factors that would be expected to lower the natural rate, including the changing demographic composition of the workforce, changes in disability policies, and improved efficiency of the labor market's matching process. Based on internal evaluation of those factors, the CBO began to lower its estimate of the NAIRU for the period since 1990, overriding the econometric estimate at that time. ${ }^{7}$

More recent Phillips curve estimates are consistent with the hypothesis that a change occurred sometime during the past 20 or so years. In a recent working paper, I presented regression results from estimates of several Phillips curve specifications that suggested the presence of significant structural change since the mid-1980s. ${ }^{8}$ Using the full data sample, from 1955 through 2007, the equations' performance appeared to be satisfactory. They fit the data well and their estimated coefficients had the correct sign, were of reasonable magnitude, and were statistically significant. However, the full-sample regressions masked evidence of a breakdown in performance that began during the mid-1980s. Estimation results from equations that allowed for structural change indicated that the fit of the equations dete-

\footnotetext{
7 That analysis was later summarized in a CBO paper; see Brauer (2007).

8 See Arnold (2008).
} 
Figure 7

\section{Married-Male Unemployment and the Change in Inflation}

Early Sample (1957-90)

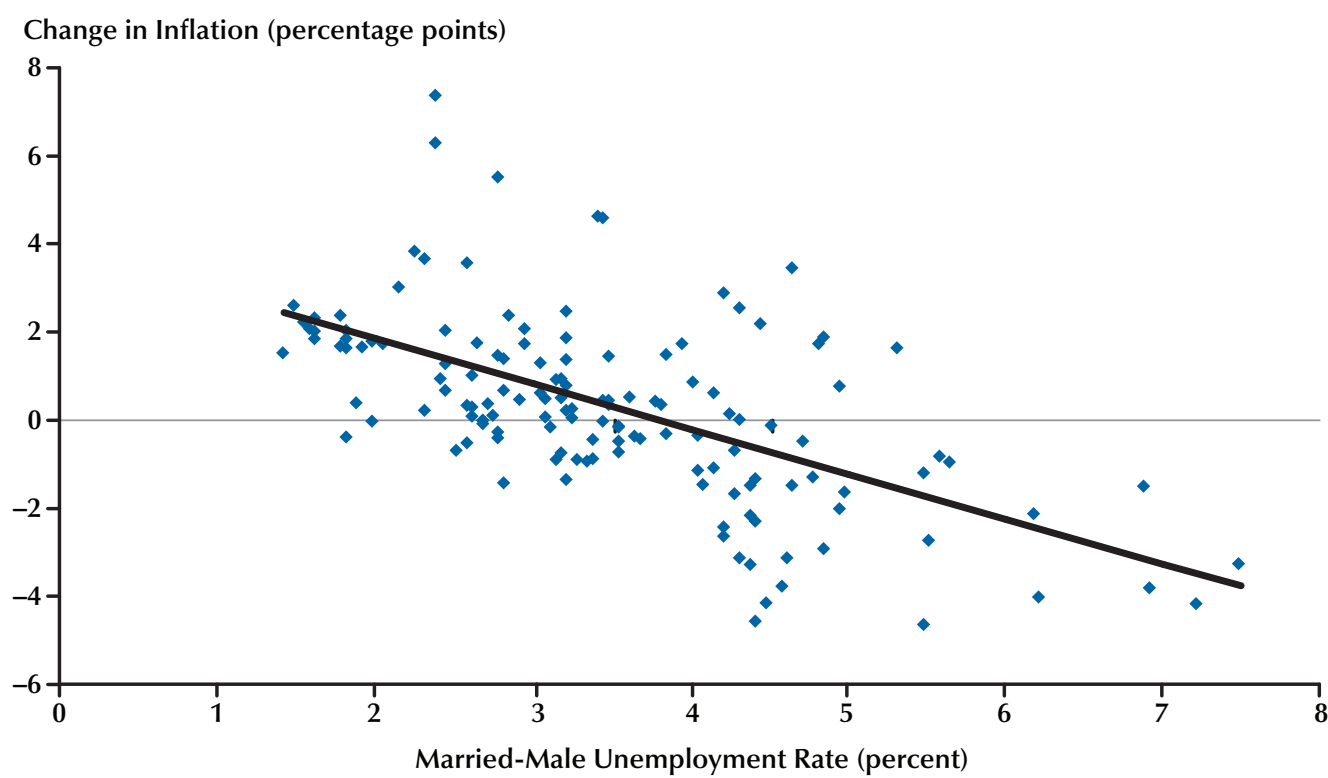

Late Sample (1991-2007)

Change in Inflation (percentage points)

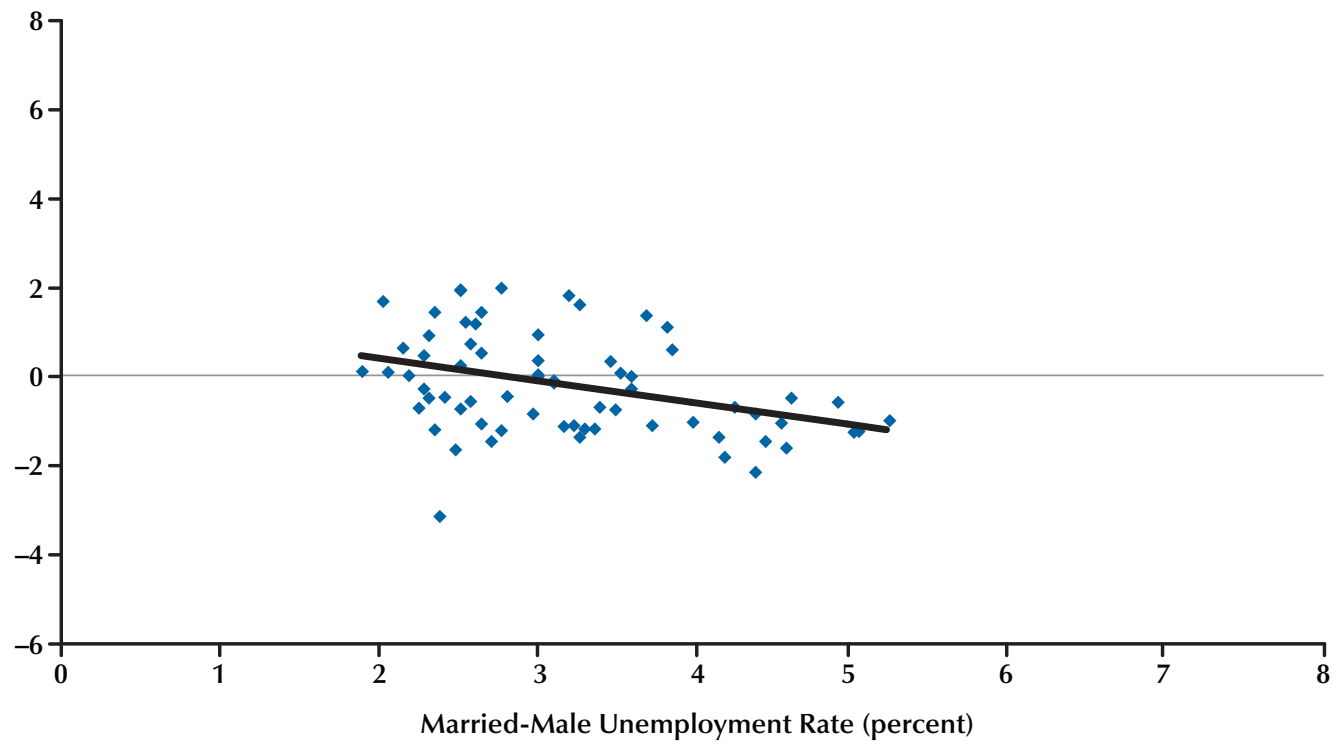

NOTE: The change in inflation is defined as the difference between the quarterly rate of inflation in the personal consumption expenditure (PCE) price index and a 24-quarter moving average of PCE inflation. 
riorated and that the coefficients were smaller and less statistically significant during the latter part of the data sample than they were during the earlier part. In general, the results suggest that the NAIRU is lower now than it had been during the period from 1955 through the mid-1980s, a conclusion consistent with evidence from the labor market suggesting a decline in the natural rate. The results also indicate that the Phillips curve has become less useful for predicting inflation.

However, the relationship between inflation and unemployment, though not as strong as it once was, has not collapsed completely. Consider Figure 7, which plots changes in a measure of unanticipated inflation against the married-male unemployment rate. The top panel shows data from the 1957-90 period, while the bottom panel shows data from 1991 through 2007. ${ }^{9}$ Comparing the two panels reveals four features of the latter period. First, both graphs show a negative correlation between the two series, so there still appears to be a tradeoff between inflation and unemployment. Second, the point at which the regression line intersects the horizontal-axis intercept has moved to the left in the second panel, which is consistent with the idea that the NAIRU is lower now than it had been earlier. Third, the slope of the trend line is lower during the second part of the sample, which suggests that the inflationunemployment tradeoff is somewhat flatter during the second period (i.e., inflation is less responsive to changes in the unemployment rate). Fourth, much less variation has occurred in both inflation and unemployment during the past 20 or so years than previously.

What do these observations imply for the estimate of potential output? The first observationthat a negative correlation still exists-means that the unemployment rate is still consistent with a stable rate of inflation. The second observationthat the NAIRU has declined-implies that the level of potential output is higher than it would

\footnotetext{
9 The working paper estimated Phillips curve equations using different price indices and used Chow tests to determine when the structural break occurred in each equation. For the personal consumption expenditures price index, the break was found in 1991. The married-male unemployment rate was used in the estimation because it is better insulated from demographic shifts than the overall unemployment rate.
}

have been had the NAIRU been constant. This observation also serves as a reminder that structural change in macro equations is a fact of life. It is important to monitor such equations continually to identify how economic events will affect their conclusions. The final two observations imply that Phillips curves, and by extension the NAIRU and potential output, are less useful indicators of inflationary pressure than they once were.

\section{Challenges Associated with Projecting Potential Output}

Potential output is used for more than gauging the state of the business cycle. It is also used to set the path for real GDP in the 10-year forecast that underlies the CBO budget projections. A separate set of challenges is associated with projecting the variables that underlie our estimate of potential output.

\section{Projecting Labor Productivity I: The Late-} 1990s' Acceleration. Labor productivity growth during the late 1990s provides an important example of the challenges associated with projecting potential GDP. ${ }^{10}$ The broad outlines of the story are familiar: After a long period of sluggish growth, labor productivity accelerated sharply during the second half of the 1990s and continued to grow rapidly during the 2000s. Moreover, the upswing was substantial. Trend growth in labor productivity averaged 2.7 percent between the end of 1995 and the middle of 2008, considerably faster than the 1.4 percent pace from 1974 to 1995 (Figure 8). Had it followed that pre-1996 trend of 1.4 percent instead of growing as it did, labor productivity would be 15 percent lower than it is today. Furthermore, if the 2.7 percent trend is sustained over the next decade, then the level of real GDP will be nearly 30 percent higher in 2018 than the level that would have resulted from the pre-1996 rate of growth.

One problem for forecasters was that the productivity acceleration was largely unexpected. In the mid-1990s, few analysts anticipated such a dramatic increase in the trend rate of growth.

\footnotetext{
${ }^{10}$ In our model, we actually project potential TFP-the projection for potential labor productivity is implied by the projections for potential TFP and capital accumulation.
} 


\section{Figure 8}

\section{Labor Productivity Growth and Trend (1950-2008)}

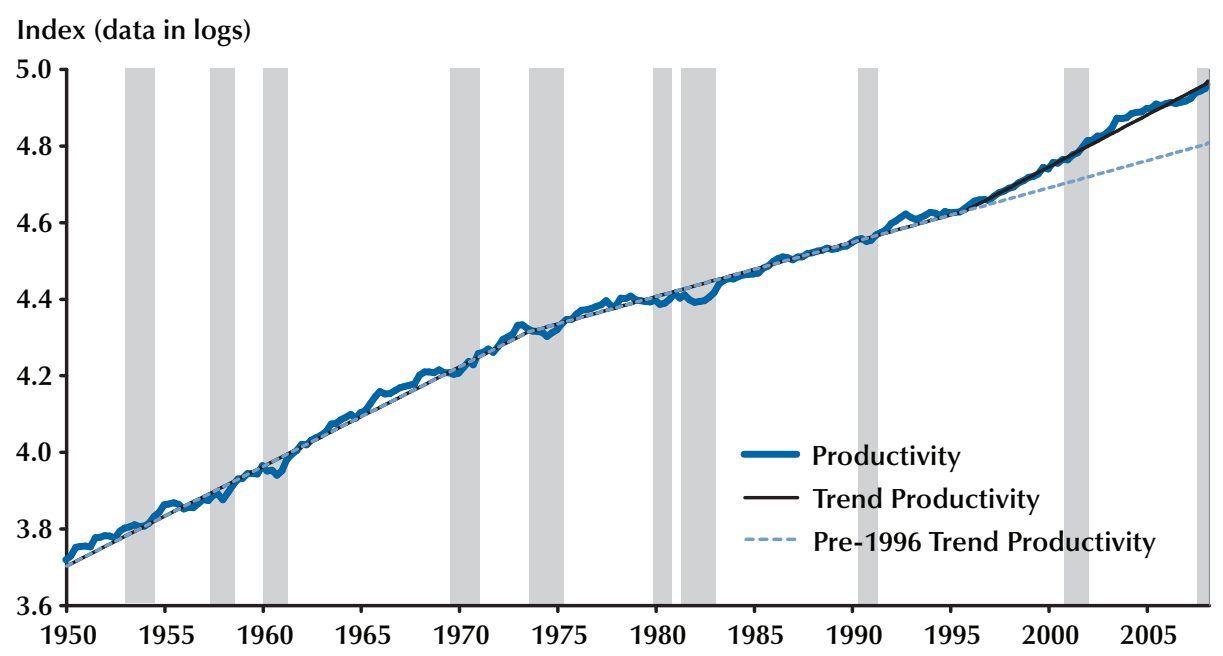

In January 1995, for example, the CBO projected that labor productivity growth would average 1.3 percent annually for the $1995-2000$ period, a pace similar to the average for the prior 20 years. The Clinton administration and the Blue Chip Consensus of private forecasters projected similar rates of growth.

Another problem for forecasters was that the productivity surge in the late 1990s went unrecognized until very late in the decade for two basic reasons. First, labor productivity is fairly volatile, with growth rates that can swing widely from quarter to quarter. As a result, a period of two or three years is a short window within which to discern a new trend. Moreover, the acceleration followed a period of subpar growth (productivity growth averaged only 0.22 percent annually between the end of 1992 and 1995:Q3); so, initially, the faster growth appeared to be just making up lost ground rather than establishing a new, higher trend growth rate. The postwar data sample includes several episodes of faster- or slowerthan-trend productivity growth that were later reversed.

Second, early vintages of productivity data for the late 1990s proved to be understated and, therefore, painted a misleading picture of the productivity trend. Only after several revisions did a stronger pattern emerge. Using real-time data culled from our forecast databases, Table 2 shows that data available in 1996, 1997, and 1998 showed only a small rise in productivity growth starting in late 1995. For example, data available in early 1997 showed labor productivity growing by only 0.3 percent on average from 1995:Q4 through 1996:Q3. The story changes markedly using currently available data: Labor productivity growth for that period was actually 3 percent.

A similar case holds for 1998 and 1999. Data available in January 1998 showed labor productivity growth averaging 1.8 percent between 1995:Q4 and 1997:Q3. That rate has since been revised upward by 0.6 percentage points, to 2.4 percent. The growth rate for the three-year period ending in 1998:Q3 also has been revised from 2.0 percent (using data from early 1999) to 2.5 percent (using currently available data).

The information in Table 2 highlights an important point. Productivity data are revised frequently, and the revisions can be large enough to alter analyses of trends in productivity growth. Indeed, after being revised upward several times during the late 1990s, productivity data have been revised downward somewhat during recent years. 
Table 2

\section{Changes in Estimates of Average Annual Growth Rate for Labor Productivity}

\begin{tabular}{|c|c|c|c|c|}
\hline \multirow[b]{2}{*}{ Date of forecast } & \multirow[b]{2}{*}{ Period } & \multicolumn{2}{|c|}{ Average annual rate of growth (\%) } & \multirow[b]{2}{*}{$\begin{array}{c}\text { Revision } \\
\text { (percentage points) }\end{array}$} \\
\hline & & $\begin{array}{c}\text { Initial estimate } \\
\text { (using original data) }\end{array}$ & $\begin{array}{l}\text { Current estimate } \\
\text { (using current data) }\end{array}$ & \\
\hline January 1997 & 1995:Q4-1996:Q3 & 0.3 & 3.0 & 2.7 \\
\hline January 1998 & 1995:Q4-1997:Q3 & 1.8 & 2.4 & 0.6 \\
\hline January 1999 & 1995:Q4-1998:Q3 & 2.0 & 2.5 & 0.5 \\
\hline January 2000 & 1995:Q4-1999:Q3 & 2.7 & 2.4 & -0.3 \\
\hline
\end{tabular}

NOTE: Each forecast is based on productivity data that extend through the third quarter of the previous year. Numbers in the table may not add up to totals because of rounding.

SOURCE: CBO based on data from the BLS.

In January 2000, labor productivity growth for 1995:Q4 to 1999:Q3 was estimated at 2.7 percent; that estimate has since been revised to 2.4 percent.

The revisions to productivity data highlight the difficulty in recognizing a change in the underlying trend growth rate and suggest that we should be circumspect about data series until they have undergone revision. This is especially true if the data show a shift in trend (as in the late 1990s) or if they are not consistent with other economic indicators.

\section{Projecting Labor Productivity II: Shifting} Sources of Growth. Another aspect of labor productivity growth during the past decade-a shift in its sources-has complicated the analysis of trends and made projections difficult. With our model we can easily divide the growth in labor productivity into two components: capital deepening (increases in the amount of capital available per worker) and TFP. Capital per worker can rise over time not only because investment provides more capital goods for workers to use, but also because the quality of those goods improves over time and investment can shift from assets with relatively low levels of productivity (e.g., factories) to those with higher productivity levels (e.g., computers). Because TFP is calculated as a residualthe growth contributions of labor and capital are subtracted from the growth in output-any growth in labor productivity that is not attributed to capital deepening will be assigned to TFP.
With this in mind, the contributions of capital deepening and TFP to the growth in labor productivity since 1995 can be calculated. The results of such a growth-accounting exercise are shown in Table 3. Those results show that capital deepening was the primary source of the surge in labor productivity growth in the late 1990s and that faster TFP growth was the primary source of productivity growth during the period after the business cycle peak in 2001. Between the early (1991-95) and the late (1996-2001) part of the past decade, labor productivity growth stepped up from about 1.5 percent, on average, to 2.5 percent per year. Growth in capital per worker accounted for 80 percent ( 0.8 percentage points) of that 1-percentage-point increase, according to our estimates. Faster TFP growth was responsible for the rest of the step-up in productivity growth, or about 0.2 percentage points.

Since the 2001 recession, however, the sources of labor productivity growth have completely reversed. Business investment fell substantially in 2001 and 2002 and remained weak in 2003, thus slowing the growth in capital deepening relative to that in the late 1990s. Consequently, the contribution of capital per worker to labor productivity growth fell by 0.7 percentage points between 2001 and 2005 relative to the 1996-2001 period. At the same time, however, TFP growth was accelerating sharply, especially in 2003. The CBO estimates that TFP was responsible for all 


\section{Table 3}

\section{Contributions of Capital Deepening and TFP to Labor Productivity Growth (1990-2006)}

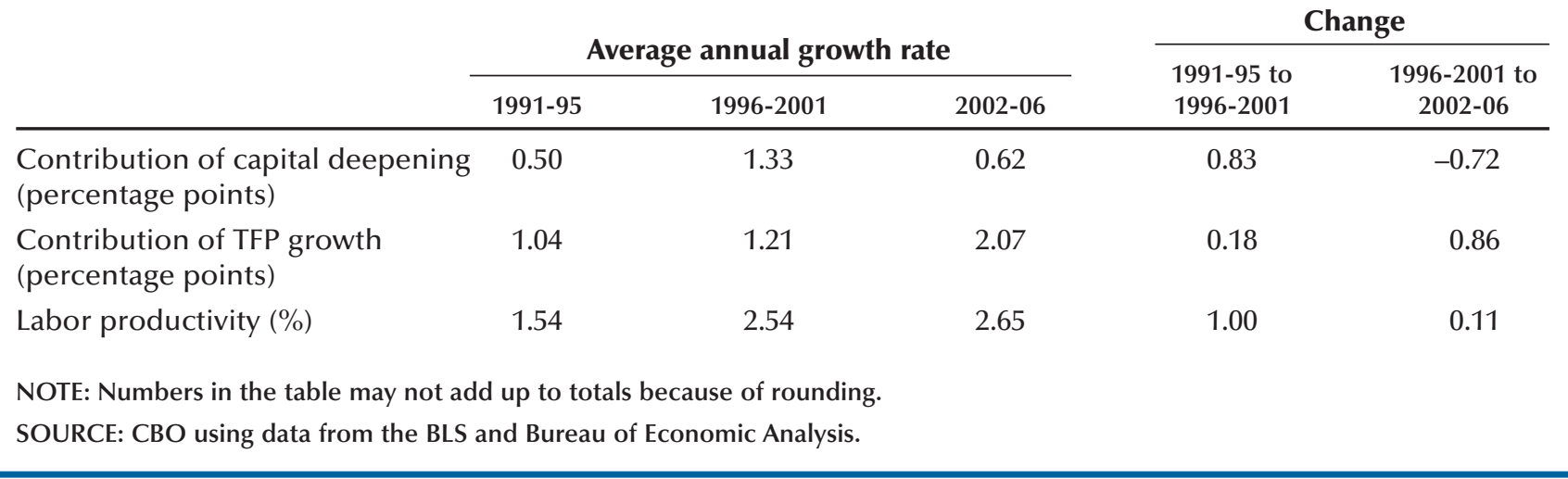

of the acceleration in labor productivity in the 2001-06 period.

A natural question is whether labor productivity will grow as rapidly over the next 10 years as during the past decade. But the experience since 1995 illustrates why that question is so hard to answer. Labor productivity growth is volatile, its measurement is subject to large revisions, and the reasons for changes in its rate of growth are not well understood. Consequently, it is a difficult variable to forecast; past patterns and recent data provide only a rough guide to future labor productivity. Explanations for the recent acceleration help to determine whether any of the changes to growth since 1995 will reverse or recur in the next 10 years.

Projecting Labor Productivity III: Explaining the Acceleration. Although it is hard to say conclusively that one factor is the sole cause of the post-1995 acceleration in productivity growth, most economists point to IT as the primary source. This case is easiest for the late 1990s and more difficult for the period since 2001. As noted previously, the majority of the productivity acceleration for 1996-2000 can be attributed to capital deepening, which was one result of a huge increase in business investment. During the late 1990s, not only did investment boom, but it was heavily tilted toward IT capital (Figure 9). The CBO estimates suggest that faster capital deepening accounted for 80 percent of the upswing in labor productivity growth during the late 1990s and that IT capital accounted for 75 percent of the contribution from capital deepening.

In addition, it appears that rapid technological change in IT industries (including computers, software, and telecommunications) caused faster TFP growth in those industries. It also appears that the pace of technological change was fast enough, and those industries were large enough, for faster TFP growth in that sector of the economy to support overall TFP growth during the late 1990s. ${ }^{11}$ However, because TFP growth did not accelerate during the late 1990s, it appears that faster TFP growth in the IT sectors merely offset slower TFP growth elsewhere.

It is somewhat harder to make the case that IT spending was the primary source of the continued rapid growth in labor productivity since the business cycle peak in 2001. One obvious problem with this explanation is that spending on IT capital collapsed after 2000, which strongly suggests that IT capital was not the reason for the continued surge. According to our estimates, nearly 80 percent of the post-2001 growth in labor productivity can be attributed to TFP, with only 20 percent accounted for by capital deepening.

Despite those estimates, the continued growth in labor productivity could still be the result of

\footnotetext{
${ }^{11}$ According to estimates by Oliner and Sichel (2000), for example, the computer and semiconductor industries accounted for about half of TFP growth from 1996 through 1999, even though those industries composed only about 2.5 percent of GDP in the NFB sector during those years.
} 


\section{Figure 9}

\section{Investment in Producers' Durable Equipment}

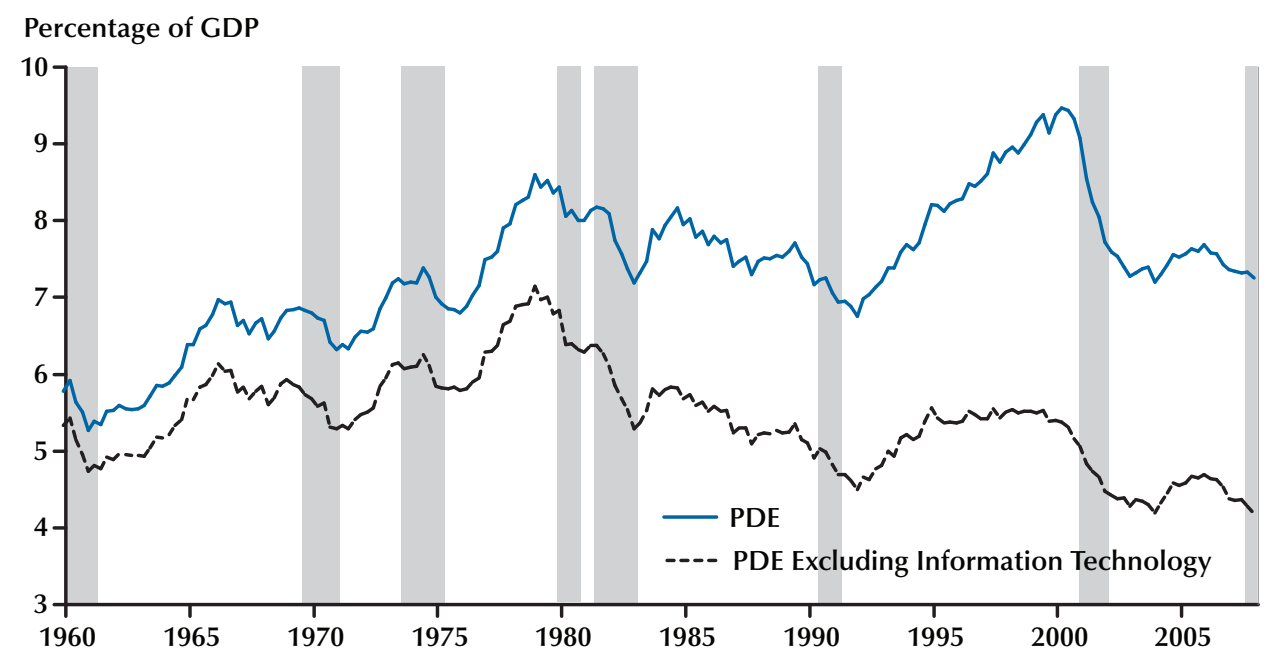

IT spending if a lag exists between the time when the capital is installed and when businesses achieve productivity gains. Several theories, not necessarily mutually exclusive, have been proposed to explain why such a delay could occur. They include the possibility that there are adjustment costs associated with large changes in the capital stock; the possibility that computers are an example of a general-purpose technology, like dynamos and electric motors, that fundamentally change the way businesses operate but take time to produce results; and the possibility that there is a link between IT spending and investment in intangible capital, which refers to spending that is intended to increase future output more than current production but does not result in ownership of a physical asset. As computing power becomes cheaper and more pervasive, managers can invent new business processes, work practices, and organizational structures, which in turn allow companies to produce entirely new goods and services or to improve their existing products' convenience, quality, or variety.

All of these theories could explain the increase in TFP growth. However, all would be expected to have a gradual effect on TFP, raising the growth rate by a small amount over an extended period. In fact, the TFP data display a very steady trend during the 1980s, 1990s, and early 2000s; then a very abrupt increase, occurring entirely in 2003; and then a return to the previous growth trend thereafter (Figure 10). This behavior is somewhat puzzling and hard to reconcile with explanations that rely on a lagged impact of IT spending during the late 1990s. We interpret the abrupt increase as a one-time boost to productivity engendered by the IT revolution-the burst of investment in IT capital allowed firms to raise their efficiency to a higher level but not to permanently increase the rate of productivity growth. Our estimate of potential TFP includes an adjustment that temporarily raises its growth rate to include a level shift similar to that shown in Figure 10.

\section{CONCLUSION}

Potential output is a difficult variable to estimate largely because it is an unobservable concept. There are many ways to compute the economy's productive potential. Some methods rely on purely statistical techniques. Others, including the CBO method, rely on statistical procedures 


\section{Figure 10}

\section{TFP and Trend (1980-2008)}

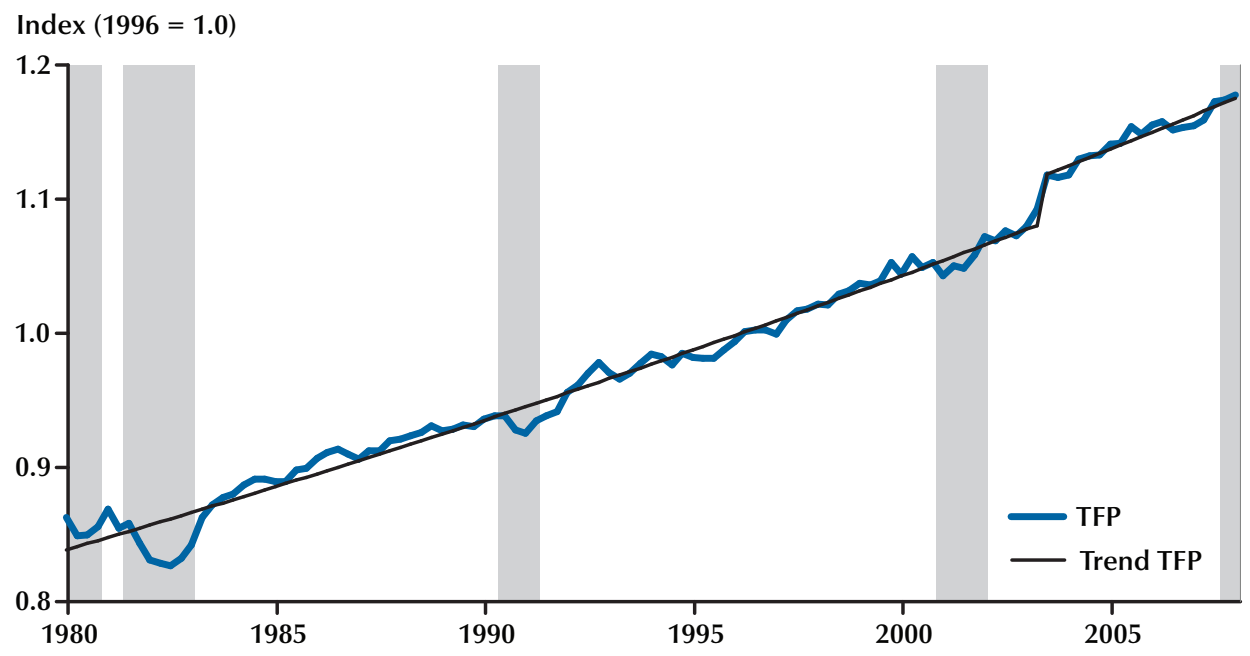

NOTE: Data are adjusted to exclude the effects of methodological changes in the measurement of prices.

grounded in economic theory. However, all of the methods have difficulty estimating the trend in GDP near the end of the data sample, which is usually the period of greatest interest. Because the trend at the end of the data sample is the trend that is projected into the future, any errors in estimating the end-of-sample trend will be carried forward into the projection. The process is further complicated by factors that alter the interpretation of recent economic events, including data revisions and structural change.

In addition to describing the CBO method and highlighting the pros and cons of our approach, this paper describes how we dealt with some developments during the past several years that complicated estimation of potential output. As a general principle, we try to make our estimate of potential output as objective as possible, but as this review of recent problems indicates, estimating potential GDP in real time often involves weighing contradictory evidence. Deciding whether or not, or how much, to change a trend growth rate for TFP, for example, often has a large effect on the estimate of potential for the medium term.
This review demonstrates that the economic landscape is continually changing and that estimates of the trend in any variable, including potential GDP, are affected by those changes. Oftentimes, what looks like a new trend in a series disappears after successive revisions. This factor argues for a conservative approach to estimating such trends and being judicious about changes in those trends.

\section{REFERENCES}

Arnold, Robert. "Reestimating the Phillips Curve and the NAIRU." Working Paper 2008-06, Congressional Budget Office, August 2008; www.cbo.gov/ftpdocs/95xx/doc9515/2008-06.pdf.

Brauer, David. "The Natural Rate of Unemployment." Working Paper 2007-06, Congressional Budget Office, April 2007; www.cbo.gov/ftpdocs/80xx/doc8008/2007-06.pdf.

Congressional Budget Office. CBO's Method for Estimating Potential Output: An Update. Washington, DC: Government Printing Office, 


\section{Arnold}

August 2001; www.cbo.gov/ftpdocs/30xx/doc3020/

PotentialOutput.pdf.

Congressional Budget Office. "CBO's Projections of the Labor Force." CBO Background Paper, September 2004; www.cbo.gov/ftpdocs/58xx/ doc5803/09-15-LaborForce.pdf.

Congressional Budget Office. The Budget and Economic Outlook: An Update. Washington, DC: Government Printing Office, September 2008; www.cbo.gov/ftpdocs/97xx/doc9706/ 09-08-Update.pdf.

Okun, Arthur M. "Potential GNP: Its Measurement and Significance," in The Political Economy of Prosperity. Appendix. Washington, DC: Brookings Institution, 1970; pp. 132-45.

Oliner, Steven and Sichel, Daniel. "The Resurgence of Growth in the Late 1990s: Is Information Technology the Story?" Journal of Economic Perspectives, Fall 2000, 14(4), pp. 3-22.

Stock, James and Watson, Mark. "Variable Trends in Economic Time Series." Journal of Economic Perspectives, Summer 1988, 2(3), pp. 147-74. 